\title{
Optimization of Silicon Leaching for White Carbon Black Preparation from Vanadium-Extraction Residue Using Response Surface Methodology
}

\author{
SHUN WANG ${ }^{1}$, SHENXU BAO ${ }^{1,2,3^{*}}$, YIMIN ZHANG ${ }^{1,2,3,4}$, YIZHONG YUAN ${ }^{4}$ \\ ${ }^{1}$ School of Resources and Environmental Engineering, Wuhan University of Technology, Wuhan 430070, PR China \\ ${ }^{2}$ Hubei Key Laboratory of Mineral Resources Processing and Environment, Wuhan 430070 \\ ${ }^{3}$ State Environment Protection Key Laboratory of Mineral Metallurgical Resources Utilization and Pollution Control, \\ Wuhan University of Science and Technology, Wuhan 430081, PR China \\ ${ }^{4}$ Hubei Collaborative Innovation Center for High Efficient Utilization of Vanadium Resources, Wuhan University of \\ Science and Technology, Wuhan 430081, PR China
}

\begin{abstract}
Vanadium-extraction residue (VER) is rich in silicon and the high temperature and high pressure alkali leaching can be used to prepare white carbon black (WCB). The effects of the mass ratio of alkali to slag, liquid-solid ratio, reaction temperature and reaction time on the silica leaching ratio were investigated. Response surface methodology was used to analyze the interaction of these main leaching parameters and the final regression equation can be obtained. By using the regression equation, the leaching schemes can be designed as the maximum leaching ratio of silica was set, thereby the optimal leaching parameters also can be obtained to reduce the leaching cost. Repeated experiments showed that the optimized leaching ratio can reach $95.26 \%$ which was just lower the predicted value by $2.17 \%$, indicating that the regression equation was reliable to be used to optimize the leaching process. The WCB product with specific surface area of $105.1 \mathrm{~m}^{2} / \mathrm{g}$ was verified by XRD and FTIR.
\end{abstract}

Keywords: white carbon black, waste utilization, response surface methodology, silica, XRD, FTIR

\section{Introduction}

Vanadium-bearing shale is an important vanadium resource in China, and the vanadium reserves in it are much larger than that in vanadium-titanium magnetite. Vanadium-extraction residue (VER) is the main solid waste produced in vanadium extraction from vanadium-bearing shale [1-4]. Approximately 120-150 tons VER is generated for every ton $\mathrm{V}_{2} \mathrm{O}_{5}$ production from the shale due to the low vanadium grade in the shale (c.a. 0.8 1.5\%) [5]. Currently, the enormous residues are generally stored in the open air, which occupies the vast amount of land and causes potential geological disaster [6]. Moreover, the accumulated VER also leads to serious threat to the environment due to the presence of heavy metals and the remaining chemical agents. Therefore, the utilization and treatment of VER has attracted a great deal of attention.

It has been studied to prepare geopolymers, autoclaved bricks, blocks and other building materials by using VER over the years [7-9]. Although these techniques, in a certain extent, can realize the utilization of VER, the added-value of these produces is low and their applications are limited. White carbon black (WCB) is a kind of amorphous silica material and is extensively applied in rubber industry, coating industry and paper industry due to its high specific strength, excellent hightemperature resistance, chemical stability, and electrical insulation as a high value-added product [10, 11]. Commonly, WCB is produced by organic silicate and inorganic silicate, for example tetraethyl orthosilicate and sodium silicate but these materials are expensive [12]. Therefore, there is an urgent need to seek an economic and alternative source of silica for the production of WCB. VER is mainly composed of silica, which can be considered as raw material for the preparation of WCB. Many studies have been attempted to prepare WCB from waste slags such as fly ash and rice hull ash [13, 14].

*email:sxbao@whut.edu.cn 
The alkali treatment-chemical precipitation method is widely adopted to prepare WCB from these waste slags [15], i.e., the silica component in the silica-rich materials is firstly converted into a soluble silicate by alkali leaching $[16,17]$ and then $p \mathrm{H}$ value of the leachate is adjusted with acid to obtain WCB product. The process flow chart is shown in Figure 1. The production processes are commonly carried out under ambient temperature and pressure at present, but it is not feasible for VER because most silica component in VER is quartz resulting in the leaching ratio of silica is low the process is time-consuming [18]. Thus, it is necessary to develop an efficient production technique for WCB from VER. In this study, a high-temperature alkali reaction-precipitation method was developed to increase the leaching ratio of silica. There are few studies on the leaching of silica at high-temperature environment and the existing literatures only focuses on the effect of single factors on experimental results without considering the interaction of variables, and the parameters optimization from the perspective of mathematical-statistical analysis has rarely examined.

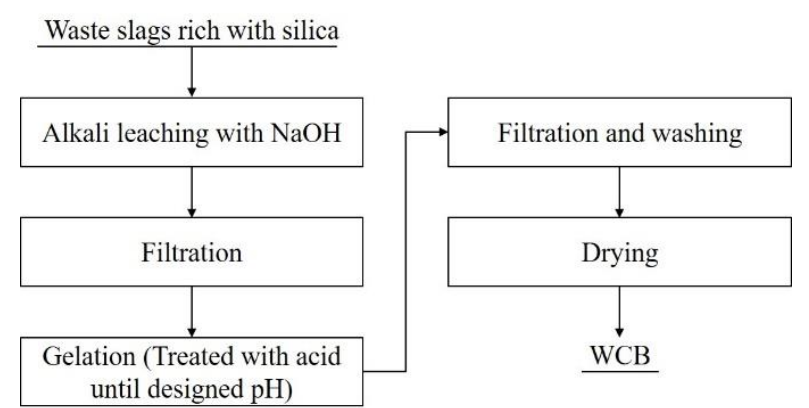

Figure 1. Flow chart of alkali leaching process

Response surface methodology (RSM) is a statistical and mathematical method helpful for experiment design and optimization of process conditions [19]. RSM determines the influence of independent variables on the process and generates a mathematically accurate description of the process model [20, 21]. It can optimize the experiments rapidly and efficiently along a path of improvement toward the general vicinity of the optimum [22]. Therefore, it not only reduces the workload of experiments but also get the best experimental conditions quickly and accurately by virtue of RSM [23].

In this study, the alkali leaching technique was used to produce WCB from VER, and the interaction effects of experimental factors on silica leaching were studied by using RSM. A prediction model of the leaching ratio of silica and experimental parameters was also established, and the prediction model was discussed by analysis of variance (ANOVA), model correction and sufficiency verification. RSM was expected to provide guidance for the WCB production in large-scale, which can realize the comprehensive utilization of the secondary resources and create environmental and economic benefits.

\section{Materials and methods}

\subsection{Materials}

The VER used for WCB production was obtained from the sodium salts roasting-water leaching technique for vanadium extraction [1]. The chemicals used in this study are sodium hydroxide and concentrated sulfuric acid (Supplied by Sinopharm Chemical Regent Co., Ltd) and deionized water was used in all experiments.

\subsection{Method of silica leaching}

Firstly, a known weight of VER was mixed with appropriate sodium hydroxide in high temperature and high-pressure reaction kettle (Beijing Century Senlong experimental apparatus Co., Ltd.) and deionized water was added to the kettle as a certain liquid-solid ratio. Then the kettle was sealed and the mixture was heated to a set temperature with constant mechanical stirring. After reaction, the kettle 
was cooled down naturally to ambient temperature and the solution was filtered, and $\mathrm{pH}$ value of the filtrate was adjusted to 8.5 by sulfuric acid to form precipitation as Equation (2). WCB can be obtained after the precipitation was filtered, washed and dried at $60^{\circ} \mathrm{C}$ in drying oven.

$$
\begin{gathered}
\mathrm{SiO}_{2}+2 \mathrm{NaOH} \rightarrow \mathrm{Na}_{2} \mathrm{SiO}_{3}+\mathrm{H}_{2} \mathrm{O} \\
\mathrm{Na}_{2} \mathrm{SiO}_{3}+\mathrm{H}_{2} \mathrm{SO}_{4}+(\mathrm{n}-1) \mathrm{H}_{2} \mathrm{O} \rightarrow \mathrm{SiO}_{2} \cdot \mathrm{nH}_{2} \mathrm{O}+\mathrm{Na}_{2} \mathrm{SO}_{4}
\end{gathered}
$$

In the high temperature leaching process, the optimal range of each condition was determined through single-factor experiments, and then the response was optimized with four factors. Finally, the verification experiments were conducted according to the optimized conditions.

\subsection{Experimental design}

\subsubsection{Single-factor leaching experiment}

The single-factor experiments were conducted to investigate and determine the effects of factors on the silica leaching in the alkali leaching process. In these univariate experiments, alkali-slag mass ratio $(1: 3,2: 3,3: 3,4: 3$ and 5:3), liquid-solid ratio $(3: 1,4: 1,6: 1,8: 1,10: 1$ and 12:1), reaction time (30, 60, $90,120,150$ and $180 \mathrm{~min})$ and reaction temperature $\left(100,120,140,160,180\right.$ and $\left.200^{\circ} \mathrm{C}\right)$ were selected. During the leaching process, other factors should be set at their maximum when one factor was examined unless the optimal value was identified.

\subsubsection{Response surface optimization}

The extent of the RSM independent variables were determined taking account into the results of the single-factor experiments: the mass ratio of alkali to slag $(A=0.5-2.0)$, liquid-solid ratio $(B=3.00-6.00)$, reaction temperature $\left(C=140-200{ }^{\circ} \mathrm{C}\right)$ and reaction time $(D=60-180 \mathrm{~min})$. Factors and their levels are shown in Table 1, and the experiments designed by the BBD (Box-Behnken design) model in Design Expert 10.0 software are shown in Table 2. Evaluated response $Y(\%)$ is the leaching ratio of silica from VER. Using the BBD model, only 29 experiments were needed to get the conclusions of 81 groups of experiments due to the fact that this study is 4 factors and 3 levels. The second-order polynomial used in the response surface is given as follows:

$$
Y=\beta_{0}+\sum_{i=1}^{4} \beta_{i} X_{i}+\sum_{i=1}^{4} \beta_{i i} X_{i}^{2}+\sum_{i=1}^{3} \sum_{i=j+1}^{4} \beta_{i j} X_{i} X_{j}
$$

where $\beta_{0}, \beta_{i}, \beta_{i i}$, and $\beta_{i j}$ are the regression coefficients for the intercept, linear, quadratic and interaction terms, respectively, and $X_{i}$ and $X_{j}$ are the independent variables [24]. The positive, negative and the magnitude of these coefficients represent the direction and strength of the experimental conditions affecting the reaction system.

The experiments were conducted according to the schemes given by BBD model (Table 2) and the experimental leaching rate can be obtained (the Y in Table 2). Then, the Design-Expert software was used to fit the BBD model by virtue of the least-squares calculation based on the experimental data and some important parameters with the help of analysis of variance (ANOVA) can be obtained, such as the value of "F", "Prob > F", "predicted R-squared $\left(R^{2}\right)$ " and "adjustment correlation coefficient $\left(R^{2}{ }_{A d j}\right)$ ". These parameters can be used to determine the simulation effect of this model. Finally, the Design-Expert software generated a three-dimensional response surface and contour plots of the dependent variable and the independent variable. These figures could help us study the interaction

\begin{tabular}{|c|c|c|c|c|c|}
\hline \multirow{2}{*}{ Independent variable } & \multirow{2}{*}{ Units } & \multirow{2}{*}{ Symbols } & \multicolumn{3}{|c|}{ Uncoded levels } \\
\hline & & & Low & Middle & High \\
\hline Mass ratio of alkali to slag & 1 & A & 0.5 & 1.25 & 2 \\
\hline Liquid-solid ratio & 1 & B & 3 & 4.5 & 6 \\
\hline Reaction temperature & ${ }^{\circ} \mathrm{C}$ & $\mathrm{C}$ & 140 & 170 & 200 \\
\hline Reaction time & $\min$ & $\mathrm{D}$ & 60 & 120 & 180 \\
\hline
\end{tabular}
between independent variables more intuitively.

Table 1 Independent variables and factor levels 
Table 2 Results of the designed experiments

\begin{tabular}{cccccc}
\hline $\begin{array}{c}\text { Experiment } \\
\text { number }\end{array}$ & $\begin{array}{c}\text { Mass ratio of } \\
\text { alkali to slag } \\
(\mathrm{A})\end{array}$ & $\begin{array}{c}\text { Liquid-solid } \\
\text { ratio } \\
(\mathrm{B})\end{array}$ & $\begin{array}{c}\text { Reaction } \\
\text { temperature } /{ }^{\circ} \mathrm{C}\end{array}$ & $\begin{array}{c}\text { Reaction } \\
\text { time/min } \\
(\mathrm{D})\end{array}$ & $\begin{array}{c}\text { Experimental } \\
\text { Leaching } \\
\text { ratio/\% } \\
(\mathrm{Y})\end{array}$ \\
\hline 1 & 1.25 & 3.00 & 170.00 & 180.00 & 87.73 \\
2 & 0.50 & 3.00 & 170.00 & 120.00 & 70.47 \\
3 & 1.25 & 4.50 & 140.00 & 60.00 & 37.71 \\
4 & 2.00 & 4.50 & 170.00 & 60.00 & 80.34 \\
5 & 1.25 & 4.50 & 170.00 & 120.00 & 87.80 \\
6 & 1.25 & 3.00 & 170.00 & 60.00 & 83.08 \\
7 & 1.25 & 4.50 & 200.00 & 180.00 & 93.25 \\
8 & 2.00 & 3.00 & 170.00 & 120.00 & 88.63 \\
9 & 0.50 & 4.50 & 200.00 & 120.00 & 82.72 \\
10 & 1.25 & 4.50 & 170.00 & 120.00 & 89.51 \\
11 & 0.50 & 4.50 & 170.00 & 180.00 & 70.95 \\
12 & 1.25 & 6.00 & 140.00 & 120.00 & 47.42 \\
13 & 1.25 & 3.00 & 140.00 & 120.00 & 56.94 \\
14 & 1.25 & 6.00 & 200.00 & 120.00 & 94.95 \\
15 & 1.25 & 6.00 & 170.00 & 180.00 & 85.87 \\
16 & 2.00 & 4.50 & 170.00 & 180.00 & 91.60 \\
17 & 1.25 & 6.00 & 170.00 & 60.00 & 82.65 \\
18 & 2.00 & 4.50 & 200.00 & 120.00 & 89.17 \\
19 & 2.00 & 4.50 & 140.00 & 120.00 & 54.81 \\
20 & 1.25 & 4.50 & 170.00 & 120.00 & 88.34 \\
21 & 0.50 & 4.50 & 140.00 & 120.00 & 32.92 \\
22 & 0.50 & 6.00 & 170.00 & 120.00 & 65.36 \\
23 & 0.50 & 4.50 & 170.00 & 60.00 & 59.14 \\
24 & 1.25 & 3.00 & 200.00 & 120.00 & 91.16 \\
25 & 2.00 & 6.00 & 170.00 & 120.00 & 84.35 \\
26 & 1.25 & 4.50 & 140.00 & 180.00 & 58.13 \\
27 & 1.25 & 4.50 & 170.00 & 120.00 & 84.98 \\
28 & 1.25 & 4.50 & 200.00 & 60.00 & 89.96 \\
29 & 1.25 & 4.50 & 170.00 & 120.00 & 89.68 \\
\hline
\end{tabular}

\subsection{Analytical method}

The chemical composition of the VER was analyzed with an X-ray fluorescence spectrometer (XRF) made by PANalytical B.V in Netherlands. The phase composition of VER and WCB product was analyzed by X-ray Diffractometer (XRD) made by Bruker-D8 in Germany working on $40 \mathrm{kV}$ instrument using a $\mathrm{Cu} \mathrm{K \alpha}$ Ni-filtered radiation $(\lambda=1.5406 \AA)$. Fourier transform infrared spectroscopy (FTIR) pattern of WCB product was acquired using Nicolet6700 made by Thermo Scientific in USA. Samples were tested at the wavenumber range of $4000-400 \mathrm{~cm}^{-1}$. The BET surface area of WCB particle was analyzed using the Nitrogen Adsorbtion-Desrobtion isotherm at $77 \mathrm{~K}$ by surface area analyzer.

The silicate content of the leaching solution was measured in accordance with silicon molybdenum blue spectrophotometry. The leaching ratio of silica was given by Equation (4):

$$
\eta=\frac{c \times V}{w \times m} \times 100 \%
$$

in which $\eta$ is the leaching ratio of silica (\%), $c$ is the silicon content of the alkali leaching solution $(\mathrm{mg} / \mathrm{L}), V$ is the volume of the alkali leaching solution $(\mathrm{mL}), w$ is the silicon content of the sample $(\mathrm{mg} / \mathrm{g}), m$ is the weight of VER $(\mathrm{g})$.

\section{Results and discussions}

\subsection{Characterization of VER}

The chemical composition of the VER is shown in Table 3. The silica content of the residue is $83.47 \%$ and other main compositions were $\mathrm{Al}_{2} \mathrm{O}_{3}, \mathrm{Fe}_{2} \mathrm{O}_{3}$, and $\mathrm{P}_{2} \mathrm{O}_{5}$, accounting for $5.09 \%, 2.40 \%$, and $1.20 \%$ respectively. By coupling with the XRD pattern of VER (Figure 2), it can be known that the 
main phase in the residue is quartz, reaching more than $80 \%$, and it can be used as raw material for producing WCB.

Table 3 Chemical composition of VER

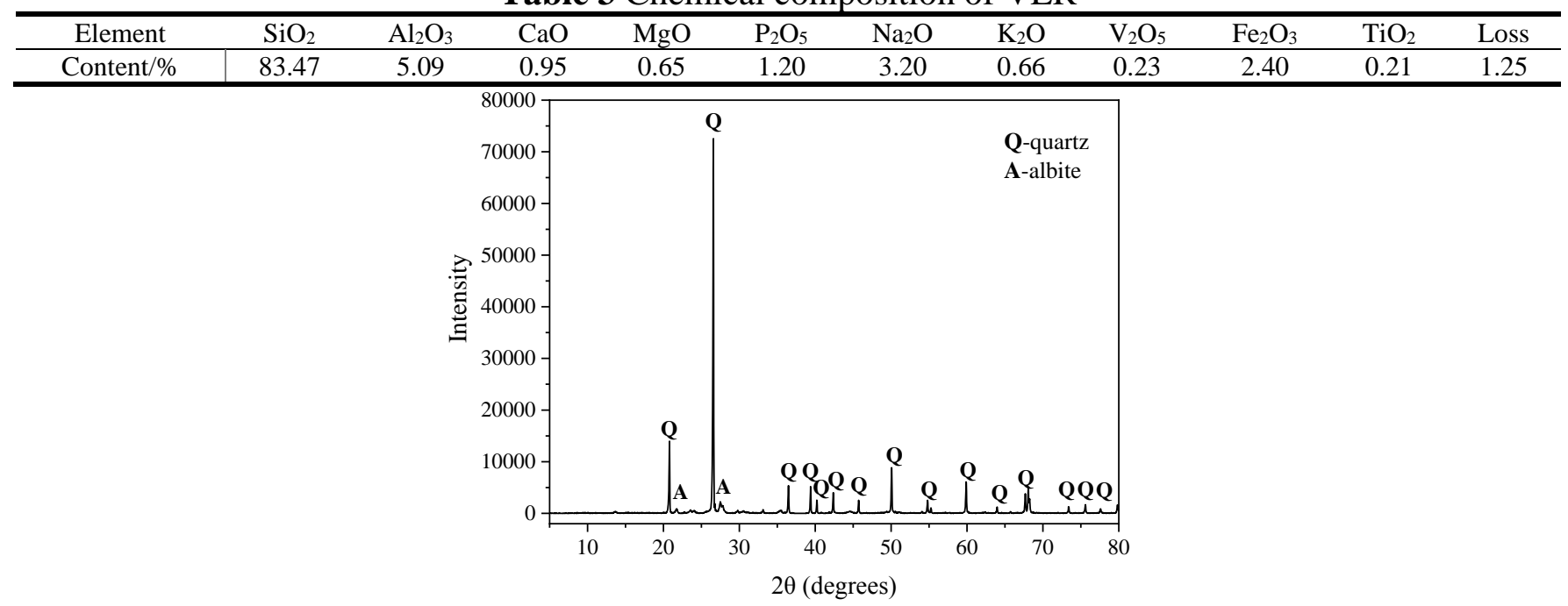

\subsection{Single-factor experiments}

Figure 2. XRD pattern of VER

\subsubsection{Effect of mass ratio of alkali to slag on leaching ratio}

The effect of alkali-slag mass ratio on the leaching ratio of silica is shown in Figure 3.

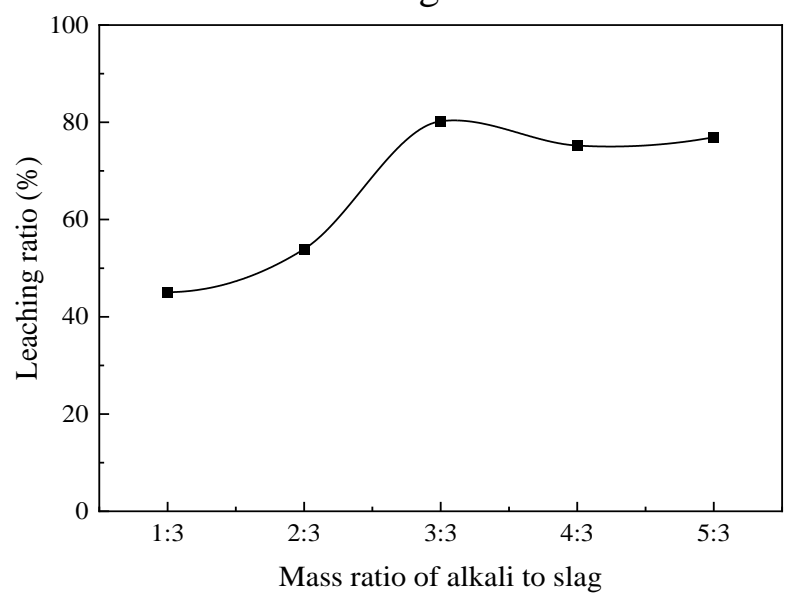

Figure 3. Effect of mass ratio of alkali to slag on leaching ratio (reaction temperature: $160{ }^{\circ} \mathrm{C}$; liquid-solid ratio: 10:1; reaction time: $120 \mathrm{~min}$ )

Figure 3 shows that the leaching ratio increases first and then decreases as the amount of alkali increases. According to the reaction principle, the more the amount of alkali added, the greater the leaching ratio is. The leaching ratio of silica decreases as the mass ratio of alkali to slag exceeds 3:3 (Figure 3), which may be due to the increased concentration of sodium silicate in the solution. High concentration of sodium silicate may lead to an increase in the viscosity of the solution, which in turn reduced the reaction rate. Furthermore, according to the content of $\mathrm{Si}$ and $\mathrm{Al}$ in the VER, the silica and the alumina can be nearly completely reacted with alkali as the mass ratio of alkali to slag is 3:3. Therefore, the alkali-slag ratio was determined to be 3:3.

\subsubsection{Effect of reaction temperature on leaching ratio}

Reaction temperature has greater impact on the leaching ratio of silica. It is clear that the leaching ratio of silica increases with the increasing temperature from Figure 4. 


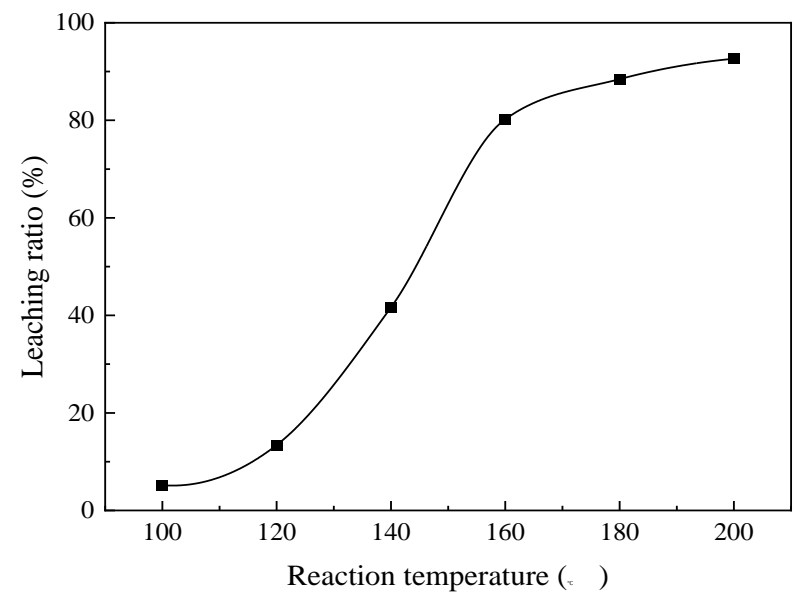

Figure 4. Effect of reaction temperature on leaching ratio (mass ratio of alkali to slag: 3:3; liquid-solid ratio:

$10: 1$; reaction time: $120 \mathrm{~min}$ )

It is clearly to see from the curve trend that the leaching ratio is sharply increased in the temperature range of 120 to $160^{\circ} \mathrm{C}$. The leaching ratio continually increases with the increasing temperature, and reaches as high as $93.93 \%$ at $200^{\circ} \mathrm{C}$ but the slope of the curve is significantly reduced after $160^{\circ} \mathrm{C}$. Thus, the reaction temperature was set as $160^{\circ} \mathrm{C}$ considering the energy consumption.

\subsubsection{Effect of liquid-solid ratio on leaching ratio}

The effect of liquid-solid ratio on the leaching ratio of silica is shown in Figure 5.

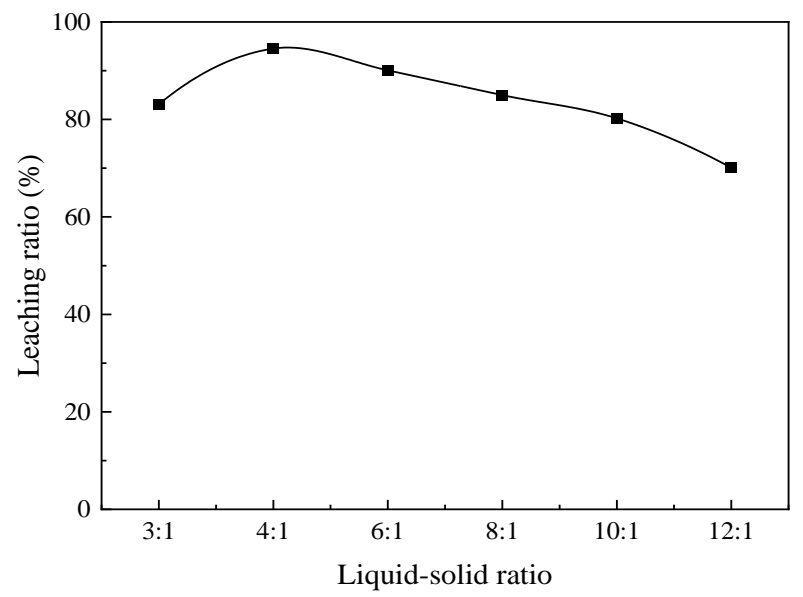

Figure 5. Effect of liquid-solid ratio on leaching ratio (mass ratio of alkali to slag: 3:3; reaction temperature:

$160{ }^{\circ} \mathrm{C}$; reaction time: $120 \mathrm{~min}$ )

As shown in Figure 5, the leaching ratio of silica increases firstly when the liquid-solid ratio changes from 3:1 to 4:1, but it drops sharply with the increasing liquid-solid ratio. As the decrease of liquid-solid ratio, the formed sodium silicate is high and it is likely to form silica coated on the surface of reactants [25], thereby influencing the leaching of silica. Therefore, the liquid-solid ratio was set preferably as $4: 1$.

\subsubsection{Effect of reaction time on leaching ratio}


The effect of reaction time on the leaching ratio of silica is shown in Figure 6. The leaching ratio is increasing much rapidly with the reaction time from 30 to $120 \mathrm{~min}$. After $120 \mathrm{~min}$, the leaching ratio tends to be stable. Therefore, the appropriate reaction time was chosen as $120 \mathrm{~min}$.

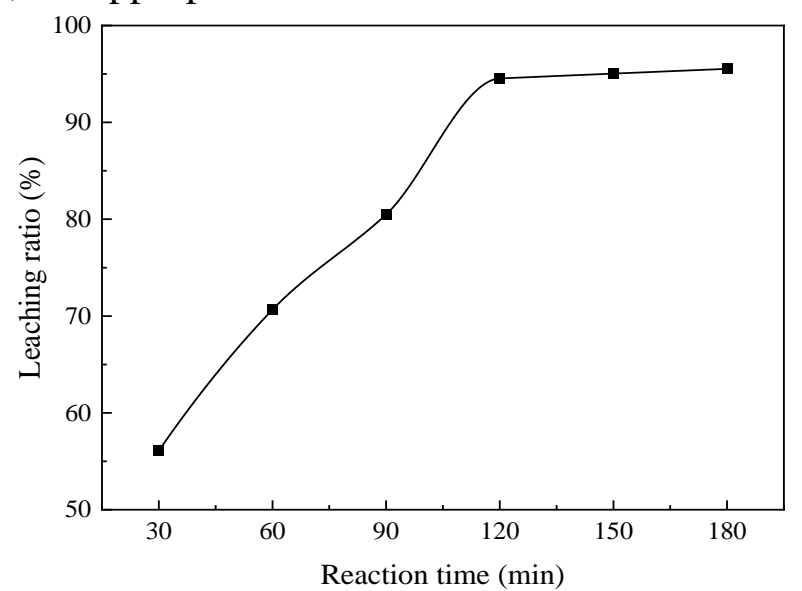

Figure 6. Effect of reaction time on leaching ratio (mass ratio of alkali to slag: 3:3; reaction temperature: $160{ }^{\circ} \mathrm{C}$; liquid-solid ratio: $4: 1$ )

\subsection{Analysis of RSM}

\subsubsection{Model fitting and ANOVA}

According to the 29 experiments given by BBD and the results in Table 2, we can get final equation in Terms of Coded Factors after fitting the experimental results as follows:

$$
\begin{gathered}
Y=88.06+9.03 A-1.45 B+21.19 C+4.55 D+0.21 A B-2.61 A C+0.36 A D+2.33 B C+ \\
0.14 B D-3.78 C D-9.36 A^{2}-0.72 B^{2}-14.53 C^{2}-2.99 D^{2}
\end{gathered}
$$

The coefficients before $A, B, C$ and $D$ represent the direction and influence of the parameters on the response. The coefficients of them are 9.03, $-1.45,21.19,4.55$ respectively, which confirms that $A, C$ and $D$ have positive impact on the response, oppositely, and $B$ 's impact on the response is negative. The order of influence is $C>A>D>B$, which shows that the reaction temperature has the greatest influence on the leaching ratio of silica.

The variance analysis of the polynomial equation is shown in Table 4 . If the $\mathrm{P}$ value is less than 0.05 , we can think that the fitting degree is better $[26,27]$. The index $\mathrm{P}$ of the model is less than 0.0001, indicating that the simulation effect of the model on this reaction system is significant and has a good regression effect. The P-value of "Lack of Fit F-value" is 0.2227 , which implies that it was not significant. This model shows a not significant "Lack of Fit F-value", reflecting the completeness of it. The other significant terms in equation (5) are $A, C, D, A C, B C, C D, A^{2}, C^{2}, D^{2}$ and their respective Pvalues are $<0.0001,<0.0001,<0.0001,0.0106,0.0236,0.0056,<0.0001,<0.0001,<0.0001$, respectively. The correlation coefficient $R^{2}$ of the model is 0.9888 , and the $R^{2}$ Adj is 0.9776 indicating that the given quadratic response surface model can fully fit the experimental data by Equation (5). Furthermore, in order to simplify the calculation of the equation, the inconspicuous terms (P-value $<0.05$ ) in Equation (5) were removed. Although the P-value for B is higher than 0.05 (Table 4), this term was retained considering $B$ is an independent variable. Thus, the simplified quadratic model can be obtained as Equation (6) and the variance analysis of the modified model is shown in Table 5.

$$
\begin{gathered}
Y=87.51+8.95 A-1.45 B+21.11 C+4.55 D-3.86 A C+3.33 B C+4.28 C D- \\
9.20 A^{2}-14.53 C^{2}-2.96 D^{2}
\end{gathered}
$$


Table 4 Variance analysis results of quadratic model

\begin{tabular}{|c|c|c|c|c|c|c|}
\hline Source & $\begin{array}{c}\text { Sum of } \\
\text { Squares }\end{array}$ & df & Mean Square & F Value & P-value Prob $>$ F & Significance \\
\hline Model & 8482.36 & 14 & 605.88 & 88.26 & $<0.0001$ & significant \\
\hline$A$ & 960.43 & 1 & 960.43 & 139.90 & $<0.0001$ & \\
\hline$B$ & 25.26 & 1 & 25.26 & 3.68 & 0.0757 & \\
\hline$C$ & 5346.11 & 1 & 5346.11 & 778.75 & $<0.0001$ & \\
\hline$D$ & 248.60 & 1 & 248.60 & 36.21 & $<0.0001$ & \\
\hline$A B$ & 0.17 & 1 & 0.17 & 0.025 & 0.8761 & \\
\hline$A C$ & 59.64 & 1 & 59.64 & 8.69 & 0.0106 & \\
\hline$A D$ & 0.076 & 1 & 0.076 & 0.011 & 0.9177 & \\
\hline$B C$ & 44.30 & 1 & 44.30 & 6.45 & 0.0236 & \\
\hline$B D$ & 0.51 & 1 & 0.51 & 0.075 & 0.7884 & \\
\hline$C D$ & 73.42 & 1 & 73.42 & 10.69 & 0.0056 & \\
\hline$A^{2}$ & 568.47 & 1 & 568.47 & 82.81 & $<0.0001$ & \\
\hline$B^{2}$ & 4.60 & 1 & 4.60 & 0.67 & 0.4265 & \\
\hline$C^{2}$ & 1368.70 & 1 & 1368.70 & 199.37 & $<0.0001$ & \\
\hline$D^{2}$ & 63.02 & 1 & 63.02 & 9.18 & 0.0090 & \\
\hline Residual & 96.11 & 14 & 6.87 & & & \\
\hline Lack of Fit & 81.73 & 10 & 8.17 & 2.27 & 0.2227 & not significant \\
\hline Pure Error & 14.38 & 4 & 3.60 & & & \\
\hline Cor Total & 8578.47 & 28 & & & & \\
\hline
\end{tabular}

Notice: $R^{2}=0.9888, R^{2}{ }_{A d j}=0.9776$

The variance analysis results indicate that this modified model is also significant ( $\mathrm{P}$-value of the model < 0.0001), and its Lack of Fit is not significant (Table 5), which implies that the modified model can still meet the requirements of response surface analysis [19]. Particularly, the P-value of $B$ was reduced from 0.0757 to 0.0485 , which became significant in the new model after simplification. Moreover, the F value of Lack of Fit 1.73 implies the Lack of Fit is not significant relative to the pure error. Non-significant lack of fit is good, in addition, the F value of Lack of Fit in the new model became smaller than Equation (5), which indicates that the former fits the experimental results better than the latter.

Table 5 Variance analysis results of the modified model

\begin{tabular}{ccccccc}
\hline Source & $\begin{array}{c}\text { Sum of } \\
\text { Squares }\end{array}$ & df & $\begin{array}{c}\text { Mean } \\
\text { Square }\end{array}$ & $\begin{array}{c}\mathrm{F} \\
\text { Value }\end{array}$ & $\begin{array}{c}\text { p-value } \\
\text { Prob > F }\end{array}$ & Significance \\
\hline Model & 8476.99 & 10 & 847.70 & 150.36 & $<0.0001$ & significant \\
$A$ & 960.43 & 1 & 960.43 & 170.36 & $<0.0001$ & \\
$B$ & 25.26 & 1 & 25.26 & 4.48 & 0.0485 & \\
$C$ & 5346.11 & 1 & 5346.11 & 948.29 & $<0.0001$ & \\
$D$ & 248.60 & 1 & 248.60 & 44.10 & $<0.0001$ & \\
$A C$ & 59.64 & 1 & 59.64 & 10.58 & 0.0044 & \\
$B C$ & 44.30 & 1 & 44.30 & 7.86 & 0.0020 & not significant \\
$C D$ & 73.42 & 1 & 73.42 & 13.02 & $<0.0001$ & \\
$A^{2}$ & 569.67 & 1 & 569.67 & 101.05 & 0.0046 & \\
$C^{2}$ & 1388.52 & 1 & 1388.52 & 246.30 & 10.44 & \\
$D^{2}$ & 58.85 & 1 & 58.85 & & & \\
Residual & 101.48 & 18 & 5.64 & & & \\
Lack of Fit & 87.09 & 14 & 6.22 & & &
\end{tabular}

\subsubsection{Model validation}

In order to further evaluate the fitting of the silica leaching by the model (Equation (6)), some important diagnostic plots, i.e. normal \% probability against internally studentized residuals, internally studentized residuals against predicted, internally studentized residuals against run number and predicted against actual, are shown in Figure 7. 

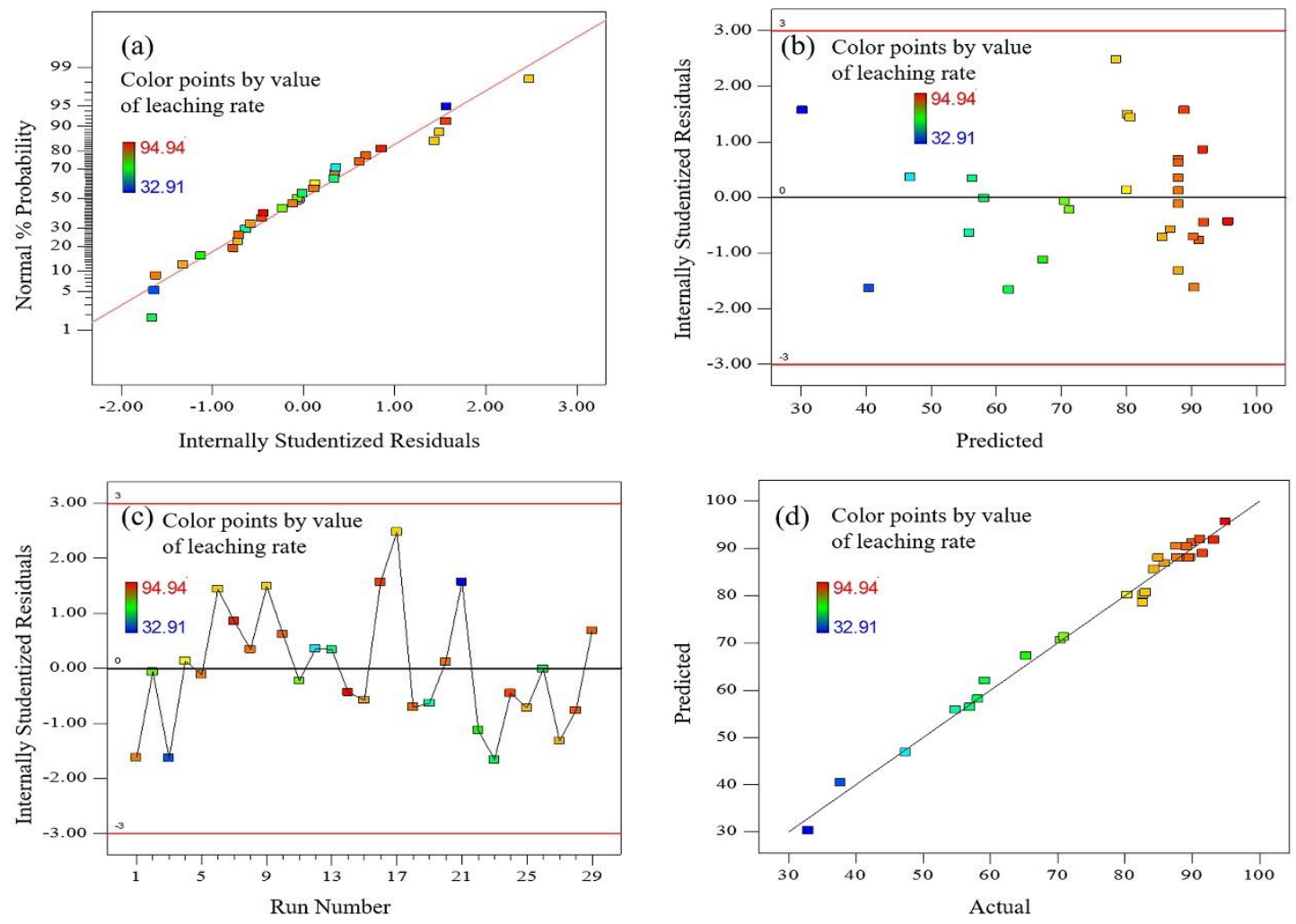

Figure 7. Diagnostic plots of the quadratic model. (a-normal \% probability against internally studentized residuals; b-internally studentized residuals against predicted; c-internally studentized residuals against Run Number; d-predicted leaching results against actual results)

It can be seen from the Normal \% Probability against Internally studentized residuals plot (Figure 7 (a)) that all points are distributed along a straight line, indicating that the error terms are normally distributed and independent of each. In Figure 7 (b) and Figure 7 (c), whether it is the predicted value or the experimental value in 29 experiments, their residuals are randomly distributed between +3.00 and -3.00 , suggesting that the BBD model can successfully establish the relationship between the independent variables and the leaching ratios [22]. The points are approximately distributed along a straight line with slope of 1 in Figure 7 (d), which indicates that this model can accurately predict the actual value.

The response surface and contour plots for the interaction effect between independent variables on the leaching ratio can be seen in Figure 8. According to the 3D response surfaces and the contour plots, the degree of interaction effect can be judged [20]. It is clear to see that the leaching ratio of silica increases with the growth of the mass ratio of alkali to slag and the temperature and then decreases gradually after it reach the maximum, as shown in Figure 8 (a), 8 (b), indicating that the excessive reaction temperature and alkali-slag mass ratio has a negative influence on the leaching ratio of silica. However, as one variable is liquid-solid ratio or reaction time, the reaction temperature always imposes the positive effect on the leaching ratio as shown in Figure 8 (c) and Figure 8 (e). The curving surface of Figure 8 (a), Figure 8 (c) and Figure 8 (e) indicates the significant interactions between mass ratio of alkali to slag and reaction temperature, liquid-solid ratio and reaction temperature, as well as reaction temperature and reaction time. As far as the influence of the individual variable is concerned reaction temperature, the mass ratio of alkali to slag, and reaction time have great influence on the leaching ratio of silica, which is accordance with Equation (6). 

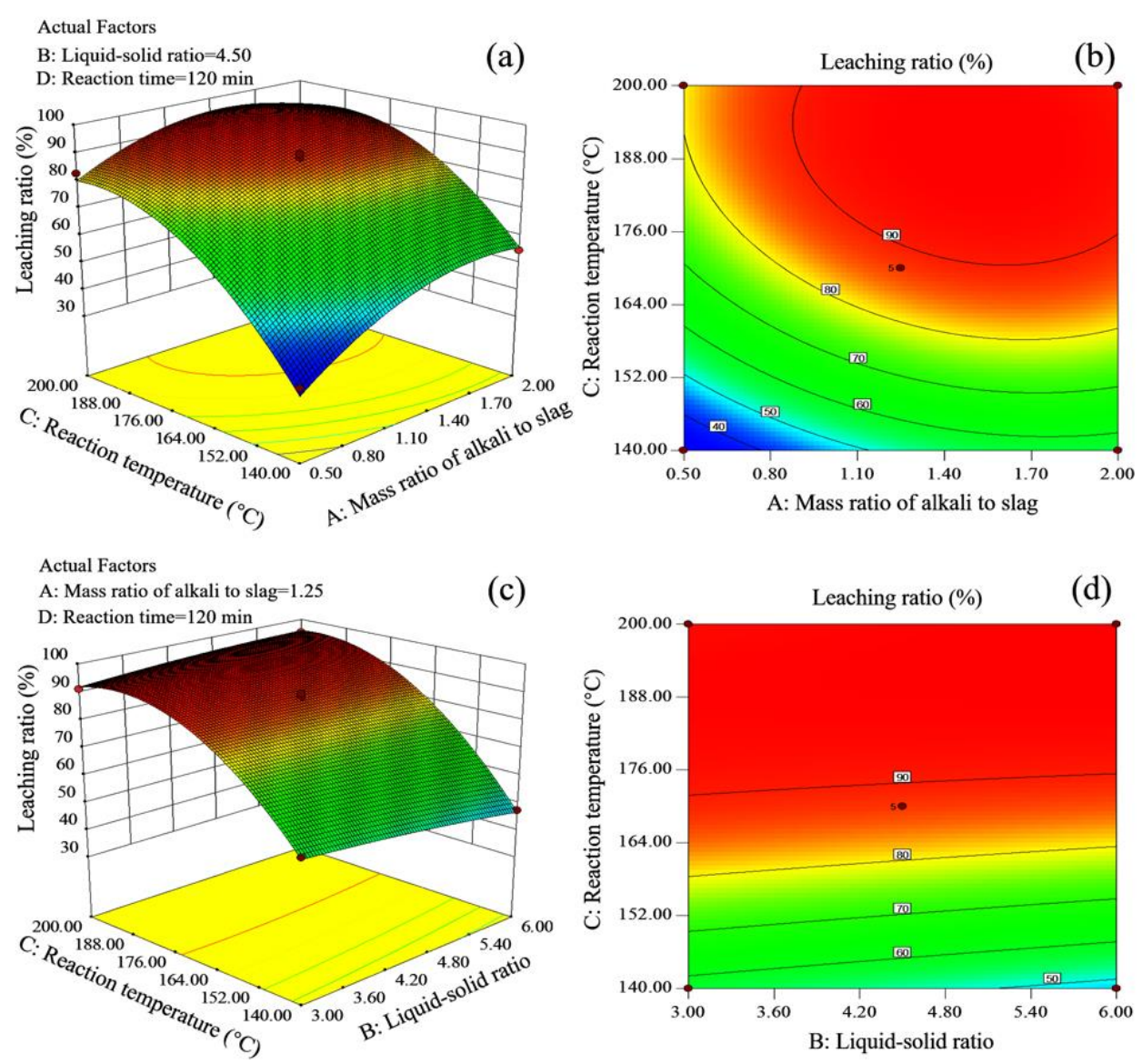

(c)
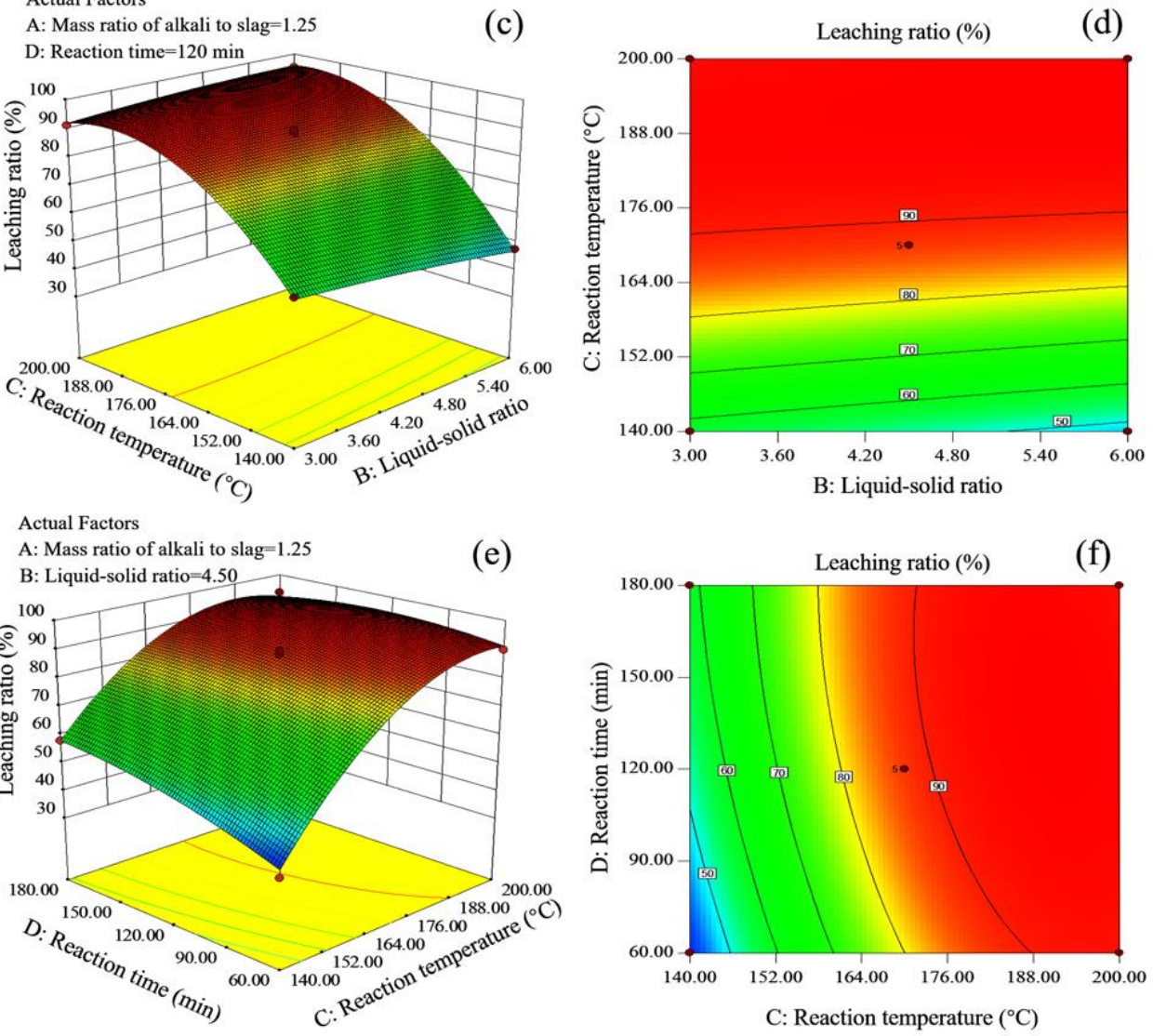

Figure 8. Response surfaces (a-mass ratio of alkali slag vs reaction temperature; c-liquid-solid ratio vs reaction temperature; e-reaction temperature vs reaction time) and contour plots (b-mass ratio of alkali slag vs reaction temperature; d-liquid-solid ratio vs reaction temperature; f-reaction temperature vs reaction time) for the interactions effect between independent variables on leaching ratio

\subsubsection{Optimization and comparison}

According to the above analysis, it indicates that the quadratic model can accurately describe the leaching process of silica from VER. Based on the fitting equation (Equation (6)) given by the model, the maximum leaching ratio was set as the target, and the software generated 30 schemes as shown in Table 6.

As can be seen from Table 6, the leaching ratios in all schemes are more than $97 \%$ with a gap of less than $0.2 \%$ except for the last three. Compared with other schemes, their liquid-solid ratios are at a low level, which will cause the solid concentration and alkali concentration in the solution to be at an 
excessive level, and long-term reactions can easily cause abrasion and corrosion on the equipment. Taking energy and alkali consumption into account, No. 26 scheme was selected and the optimal leaching conditions, i.e. mass ratio of alkali to slag is $1.48: 1$, liquid-solid ratio is $6.00: 1$, reaction time and reaction temperature are $193.8^{\circ} \mathrm{C}$ and $119.2 \mathrm{~min}$ respectively also can be determined. The verification experiments showed that real leaching ratio of silica was $95.26 \%$, and the error was only $2.17 \%$ when comparing to the predicted value $97.33 \%$, indicating that RSM can be used to predict the leaching ratio of silica.

Table 6 Optimal optimization scheme conditions and results prediction

\begin{tabular}{|c|c|c|c|c|c|c|}
\hline Number & A & $\mathrm{B}$ & $\mathrm{C} /{ }^{\circ} \mathrm{C}$ & $\mathrm{D} / \mathrm{min}$ & $\mathrm{Y} / \%$ & \\
\hline 1 & 1.49 & 6.00 & 193.30 & 132.43 & 97.46 & \\
\hline 2 & 1.49 & 6.00 & 193.46 & 131.33 & 97.46 & \\
\hline 3 & 1.50 & 6.00 & 193.04 & 133.32 & 97.46 & \\
\hline 4 & 1.49 & 6.00 & 193.13 & 130.61 & 97.46 & \\
\hline 5 & 1.50 & 6.00 & 192.96 & 134.26 & 97.46 & \\
\hline 6 & 1.48 & 6.00 & 193.54 & 132.68 & 97.46 & \\
\hline 7 & 1.50 & 6.00 & 193.78 & 131.26 & 97.46 & \\
\hline 8 & 1.49 & 6.00 & 192.87 & 131.03 & 97.46 & \\
\hline 9 & 1.49 & 6.00 & 193.48 & 135.55 & 97.45 & \\
\hline 10 & 1.50 & 6.00 & 192.61 & 131.46 & 97.45 & \\
\hline 11 & 1.50 & 6.00 & 192.47 & 132.47 & 97.45 & \\
\hline 12 & 1.49 & 6.00 & 192.08 & 135.34 & 97.44 & \\
\hline 13 & 1.52 & 6.00 & 193.52 & 128.68 & 97.44 & \\
\hline 14 & 1.51 & 6.00 & 193.85 & 126.15 & 97.43 & \\
\hline 15 & 1.46 & 6.00 & 192.95 & 137.26 & 97.42 & \\
\hline 16 & 1.44 & 6.00 & 193.68 & 133.49 & 97.42 & \\
\hline 17 & 1.46 & 6.00 & 194.91 & 126.41 & 97.41 & \\
\hline 18 & 1.50 & 6.00 & 191.85 & 140.35 & 97.41 & \\
\hline 19 & 1.56 & 6.00 & 193.08 & 133.41 & 97.40 & \\
\hline 20 & 1.53 & 6.00 & 192.40 & 140.91 & 97.40 & \\
\hline 21 & 1.48 & 6.00 & 191.74 & 127.95 & 97.39 & \\
\hline 22 & 1.55 & 6.00 & 192.53 & 139.99 & 97.38 & \\
\hline 23 & 1.48 & 6.00 & 190.65 & 135.33 & 97.36 & \\
\hline 24 & 1.48 & 6.00 & 195.30 & 137.32 & 97.36 & \\
\hline 25 & 1.42 & 6.00 & 193.42 & 138.79 & 97.34 & \\
\hline$\underline{26}$ & $\underline{1.48}$ & $\underline{6.00}$ & $\underline{193.84}$ & $\underline{119.17}$ & $\underline{97.33}$ & Selected \\
\hline$\overline{27}$ & $\overline{1.52}$ & $\overline{6.00}$ & 189.88 & $\overline{137.61}$ & 97.30 & \\
\hline 28 & 1.49 & 4.70 & 189.84 & 132.48 & 96.62 & \\
\hline 29 & 1.52 & 3.00 & 184.76 & 132.52 & 95.96 & \\
\hline 30 & 1.78 & 3.00 & 182.37 & 120.82 & 94.50 & \\
\hline
\end{tabular}

\subsection{Characterization of WCB}

The XRD peaks of produced WCB from VER are shown in Figure 9. Significant dispersion peaks appeared in the range of 20 to $25^{\circ}$, and there are no particularly sharp peaks in the figure. The diffraction peak confirms the presence of amorphous silica, which may be related to the presence of disordered cristobalite [12], which is consistent with the results of other studies [28, 29].

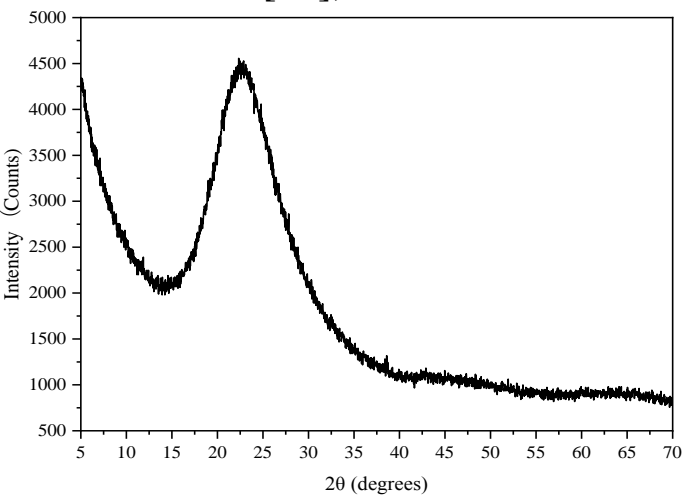

Figure 9. XRD pattern of WCB extracted

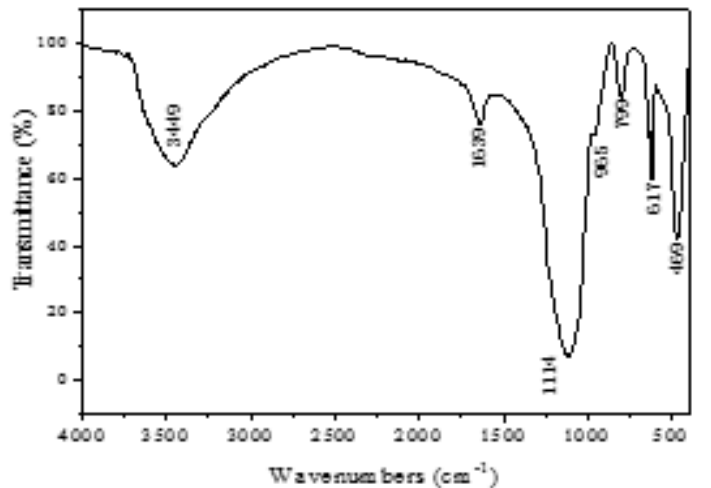

Figure 10. FTIR spectrum of WCB 
The FTIR spectrum (Figure 10) shows the major chemical groups on the WCB product. The broad peaks at 3449 and $1639 \mathrm{~cm}^{-1}$ are due to the stretching vibration of the $\mathrm{H}-\mathrm{O}-\mathrm{H}$ and $\mathrm{O}-\mathrm{H}$ bond respectively, which can be assigned to the presence of absorbed water on the surface of the product [30,31]. The strong absorption peak at $1114 \mathrm{~cm}^{-1}$ is due to the asymmetric stretching vibration of the siloxane bonds ( $\mathrm{Si}-\mathrm{O}-\mathrm{Si}$ ) [32-34], while the peak at $799 \mathrm{~cm}^{-1}$ is assigned to the Si-O-Si symmetric bond stretching vibration and the peak at $469 \mathrm{~cm}^{-1}$ is associated with the bending vibration modes of network O-Si-O [35]. The weak absorption peak at $956 \mathrm{~cm}^{-1}$ is ascribed to the bending vibration of Si$\mathrm{OH}$ [36]. These bonds indicate that the obtained product is amorphous hydrated silica, i.e. WCB, which is also confirmed by XRD analysis.

The specific surface area of the prepared WCB product was measured as $105.1 \mathrm{~m}^{2} / \mathrm{g}$, which is similar to the specific surface area of the silica prepared by Wang et al [37], the researcher added it into the rubber as additive successfully. The hydroxyl groups on the surface of WCB form a physical and chemical bond with rubber molecules, and a molecular adsorption layer is formed on the surface of WCB to enhance the reinforcing effect of rubber [38, 39]. So it can be used as reinforcing or flowaid reagent in rubber.

\section{Conclusions}

RSM was used in this study to optimize the high temperature and high pressure alkali leaching process of silica from VER for preparation of WCB. The quadratic equation can be obtained by analyzing the experimental results by using the BBD model. This equation can fit the leaching process well and it can be used to design the leaching parameters and to predict the leaching ratio of silica. A variety of leaching schemes can be obtained if the leaching ratio was set by using the quadratic equation and the optimal conditions for preparing WCB, i.e. mass ratio of alkali to slag is 1.48:1, liquid-solid ratio is 6.00:1, reaction time and reaction temperature are $193.8^{\circ} \mathrm{C}$ and $119.2 \mathrm{~min}$ respectively, can be determined by taking energy and alkali consumption into account. Under these conditions, the actual leaching ratio of silica was $95.26 \%$ which is close to the predicted value $97.33 \%$, indicating that the equation is reliable to determine the parameters in the silica leaching process. The XRD, FTIR were used to verify the product with a surface area of $105 \mathrm{~m}^{2} / \mathrm{g}$, and the results showed that the product was WCB.

Acknowledgement: This research was supported by the Major Technical Innovation Project of Hubei Province (2018ACA157); the National Natural Science Foundation of China (51874222).

\section{References}

1. ZHANG Y.M., BAO S.X., LIU T., CHEN T.J., HUANG J., The Technology of Extracting Vanadium from Stone Coal in China: History, Current Status and Future Prospects, Hydrometallurgy, 109, 2011, 116-114.

2. LUO Y.P., BAO S.X., ZHANG Y.M., Preparation of One-Part Geopolymeric Precursors Using Vanadium Tailing by Thermal Activation, J. Am. Ceram. Soc., 103, 2020, 779-783.

3. CHEN B., BAO S.X., ZHANG Y.M., Column Separation of Vanadium (V) from Complex Sulfuric Solution Using Trialkylamine-Impregnated Resins, JOM, 72(2), 2019, 953-961.

4. YUAN Y.Z., ZHANG Y.M., LIU T., CHEN T.J., Microwave Roasting with Size Grading Based on The Influence of Carbon on Vanadium Extraction from Stone Coal via Microwave Roasting-Acid Leaching, RSC. Adv., 7(3), 2017, 1387-1395.

5. CHEN B., BAO S.X., ZHANG Y.M., LI S., A High-Efficiency and Sustainable Leaching Process of Vanadium from Shale in Sulfuric Acid Systems Enhanced by Ultrasound, Sep. Purif. Technol., 240, $2020,116624$.

6. MENG R., LIU T., ZHANG Y.M., YUAN Y.Z, HU P.C., Synchronous Activation of Si and Al in Vanadium-Bearing Shale Leaching Residue via Sodium Carbonate Additive, Constr. Build. Mater., 170(May. 10), 2018, 20-25. 
7. JIAO X.K., ZHANG Y.M., CHEN T.J., Thermal Stability of A Silica-Rich Vanadium Tailing Based Geopolymer, Constr. Build. Mater., 38(Jan.), 2013, 43-47.

8. LEE B., KIM G., KIM R., CHO B., LEE S., CHON C.M., Strength Development Properties of Geopolymer Paste and Mortar with Respect to Amorphous Si/Al Ratio of Fly Ash, Constr. Build. Mater., 151(Oct. 1), 2017, 512-519.

9. HU F.F., ZHANG Y.M., CHEN T.J., LIU T., SHI W., Research on Preparation of Autoclaved Brick from Stone Coal Acid-Leaching Vanadium Tailings, Metal Mine, (10), 2012, 149-152.

10. MD N.A., PRANUT P., Synthesis of Nano Zinc Hydroxide via Sol-Gel Method on Silica Surface and Its Potential Application in The Reduction of Cure Activator Level in The Vulcanization of Natural Rubber, J. Sol-Gel. Sci. Technol., 81(3), 2017, 903-911.

11. LIU Q.X., XU W.C., Study on Amorphous Silica Powder Properties, Adv. Mater. Res., 1790(1027), 2012, 2428-2433.

12. AMIN N., KHATTAK S., NOO S., FERROZE I., Synthesis and Characterization of Silica from Bottom Ash of Sugar Industry, J. Clean. Prod, 117(Mar.20), 2016, 207-211.

13. GAO G.M., ZOU H.F., GAN S.C., Preparation and Properties of Silica Nanoparticles from Oil Shale Ash, Powder. Technol., 191(1/2), 2009, 47-51.

14. KALAPATHY U., PROCTOR A., SHULTZ J., A Simple Method for Pure Silica from Rice Hull Ash, Bioresource. Technol., 73(3), 2000, 257-262.

15. AN D.M., GUO Y.P., ZHOU Y.C., WANG Z.C., A Green Route to Preparation of Silica Powders with Rice Husk Ash and Waste Gas, Chem. Eng. J., 162(2), 2010, 509-514.

16. HU W.B., LI M.M., CHEN W., ZHANG N., LI B., WANG M., ZHAO Z.M., Preparation of Hydrophobic Silica Aerogel with Kaolin Dried at Ambient Pressure, Colloid. Surface. A., 501(Jun.), 2016, 83-91.

17. HOSSAIN S.S., MATHUR L., BHARDWAJ A., ROY P.K., A Facile Route for The Preparation of Silica Foams Using Rice Husk Ash, Int. J. Appl. Ceram. Technol., 16(3), 2019, 1069-1077.

18. COSTA S.A.J., PARANHOS C.M., Systematic Evaluation of Amorphous Silica Production from Rice Husk Ashes, J. Clean. Prod., 192(Aug. 10), 2018, 688-697.

19.ZHANG Z.Y., PENG J.H., SRINIVASAKANNAN C., ZHANG Z.B., ZHANG L.B., FERNÁNDZE Y., MENÉNDZE J.A., Leaching Zinc from Spent Catalyst: Process Optimization Using Response Surface Methodology, J. Hazard. Mater, 176(1-3), 2010, 1113-1117.

20.YUAN Y.Z., ZHANG Y.M., LIU T., HU P.C., ZHENG Q.S., Optimization of Microwave Roasting-Acid Leaching Process for Vanadium Extraction from Shale via Response Surface Methodology, J. Clean. Prod., 234, 2019, 494-502.

21.STEFAN D.S., ORBECI C., Stefan M., Optimizing Enzymatic Biodegradation of Skins Waste Using Response Surface Methodology, Rev. Chim., 70(6), 2019, 2087-2090.

22.ZHU Z., ROSENDAHL L., TOOR S.S., CHEN G.Y., Optimizing The Conditions for Hydrothermal Liquefaction of Barley Strawfor Bio-Crude Oil Production Using Response Surface Methodology, Sci Total Environ., 630, 2018, 560-569.

23. DIACONESCU R.M., GRIGORIU A.M., LUCA C., GEORGESCU P., Study on The Response Surface Modelling by Central Composite Design and Optimization of Paper Nanocoating, Rev. Chim., 62(5), 2011, 522.

24. LIYANA P.C., SHAHIDI F., Optimization of Extraction of Phenolic Compounds from Wheat Using Response Surface Methodology, Food Chem., 93(1), 2005, 47-56.

25. HUA J., YAN W.B., GAO F., CAI J., LEI C., Study on Preparation of White Carbon Black from Acidic Leaching Residues of Stone Coal, Non-metallic Mines., (5), 2015, 11-13.

26.CAI W.R., TANG J., GU X.H., Extraction, Purification, and Characterization of The Polysaccharides from Opuntia Milpa Alta, Carbohyd. Polym., 71(3), 2008, 403-410.

27. QIAO D.L., KE C.L., HU B., Antioxidant Activities of Polysaccharides from Hyriopsis Cumingii, Carbohyd. Polym., 78(2), 2009, 199-204. 
28. CHEN X.Y., HUANG L.M., LI Q.Z., Hydrothermal Transformation and Characterization of Porous Silica Templated by Surfactants, J. Phys. Chem. B., 101(42), 1997, 8460-8467.

29. BJÖRK E.M., Synthesizing \& Characterizing Mesoporous Silica SBA-15: Ahands-on Laboratory Experiment for Undergraduates Using Various Instru-Mental Techniques, J. Chem. Educ., 94(1), 2017, 91-94.

30. PANIAS D., GIANNOPOULOU I.P., PERRAKI T., Effect of Synthesis Parameters on The Mechanical Properties of Fly Ash-Based Geopolymers, Colloid. Surface. A., 301(1-3), 2007, 246-254.

31. ZAWRAH M.F., EI-KHESHEN A.A., ABD E.A., HAITHAM M., Facile and Economic Synthesis of Silica Nanoparticles, J. Ovonic Res., 5(5), 2009, 129-133.

32. VELMURUGAN P., SHIM J., LEE K.J., CHO M., LIM S.S., SEO S.K., CHO K.M., BANG K.S., $\mathrm{OH}$ B.T., Extraction, Characterization, and Catalytic Potential of Amorphous Silica from Corn Cobs by Sol-Gel Method, J. Ind. Eng. Chem., 29, 2015, 298-303.

33. AMIN N., A Multi-Directional Utilization of Different Ashes, RSC. Adv., 4, 2014, 62769-62788.

34. YANG X.Y., TANG W.J., LIU X.Y., DU H., WU Y., ZHANG J.B., Synthesis of Mesoporous Silica from Coal Slag and $\mathrm{CO}_{2}$ for Phenol Removal, J. Clean. Prod., 208, 2019, 1255-1264.

35. RAHMAT N., SABALI M.A., SANDU A.V., SAHIRON N., SANDU I.G., Study of Calcination Temperature and Concentration of Naoh Effect on Crystallinity of Silica from Sugarcane Bagasse Ash (SCBA), Rev. Chim., 67(9), 2016, 1872-75.

36.ONISEI S., PONTIKES Y., VAN G.T., ANGELOPOULOS G.N., VELEA T., Synthesis of Inorganic Polymers Using Fly Ash and Primary Lead Slag, J. Hazard Mater., 205-206(3), 2012, 101110.

37.WANG B.H., XIONG Y.Z., WU S.X., JIANG M., WANG Q., ZHANG Q.P., Property Characterization of Ionic Liquid Modifying Silica, J. Synth Cryst., 46(9), 2017, 1851-1857.

38.ANSARIFAR A., AZHAR A., IBRAHIM N., SHIAH, S.F., LAWTON J.M.D., The Use of A Silanised Silica Filler to Reinforce and Crosslink Natural Rubber, Int. J. Adhes., 25(1), 2005, 77-86.

39. RYU C., YANG J.K., PARK W., KIM S.J., KIM D., SEO G., KIM B.H., Reinforcing Performance of Networked Silicas in Silica-Filled Chloroprene Rubber Compounds, Elastom. and composite., 54(1), 2019, 40-53

Manuscript received: 28.03 .2020 